\title{
A Milestone in Film History: Smartphone Filmmaking
}

\author{
Nihan Gider Iş1kman
}

\begin{abstract}
Cinema industry has changed from celluloidbased film to the digital production, distribution and release net fastly by the end of $20^{\text {th }}$ century. Changes in the classical production style led to changes in distribution and viewership trends as well. This change caused to better understand the old and to adapt to the new. Now, there is an environment in the cinema industry where analog technology has nearly completely been replaced by digital technology and in particular smartphone technologies are increasingly playing a major part in film production, distribution, and reception. Some sector professionals suggest that digital technology has led to the democratization of the cinema, whereas some point out that through the cheapness, accessibility and easy use of technology, especially smartphones in the context of this study, has led to an increase in interest in the film industry and made people believe that anyone could be a filmmaker. The aim of this study is to evaluate the effects of digitalization in cinema in terms of production, distribution, and spectatorship by focusing specially on smartphone filmmaking as an arising trend.
\end{abstract}

Index Terms-Cinema, digitalization, smartphone filmmaking.

\section{INTRODUCTION}

Cinema, which is in absolute relation with technology, constantly renewed and improved itself with new technological developments within the historical development process, and it has passed through many stages thanks to technological developments. Sound, color, and three-dimension in cinema narration are the results of technological developments. Besides digitization begun at the end of the 20th century and have made great progress in the early 21 st century has also affected and will continue to influence the cinema as an art form. In the digital era, the equipment needed for audiovisual records have become much smaller, lighter and cheaper and therefore more accessible. Likewise, it has become much easier to edit these records and get them ready for broadcasting by means of digital systems including internet. Moreover, the availability of possibilities to copy these records easily and to publish them on the internet provides easy access to viewers. Therefore the recent informatics and communication technologies have rendered possible the production, distribution and the consumption of media contents for broader parts of the society. As the borderlines between learning, working, and relaxation on the internet become more and vaguer, the smartphones, tablets, and computers that are always on and online turn everyone into both content providers and consumers of this medium.

Manuscript received July 7, 2018; revised September 29, 2018.

Nihan Gider Işıkman is with Baskent University, Turkey (e-mail: ngider@baskent.edu.tr).
Famous director Soderbergh indicates in one of his interviews this as "When I was starting out it was incredibly expensive even to make a short film, but now you have no excuse, the only obstacle is yourself." [1]

The fact that the cinema can be done by everyone should be read as democratization in the field and ability to produce their own representations. Its function has been discussed throughout history, to legitimize the representations, sovereign institutions and traditional values used and to instill ideology. It is natural to have different discourse and representation strategies for different social conditions in the cinema that cannot be considered apart from social, political and economic life. While the cinema encrypts the social discourses, it takes its place in the integrity of the system of cultural representations that build social reality. Representations that dominate a culture are of crucial political importance. They play a very important role in how social reality is to be built, that is, which figures and boundaries will dominate social life, shaping institutions.

It is important to consider the effects of technology on the creation of representations as well as on its presentation to the audience because, as Barker [2] notes, globalization is not only an economic phenomenon, it is also a cultural phenomenon and defines cultural identities as an example of world representations. Lopez [3] refers to the effects of globalization on the nature of transnational cinema in her article Facing up Hollywood. Lopez indicates that along with the 1970s, the rise of changes and developments in economic and cultural dynamics gave chance to a number of companies to catch the opportunity to present their products to the whole world and she underlines the fact that the technological transfers have also affected globalization. Together with the development of technology, it also speeds up the flow of information by removing the international boundaries.

For decades financial and technical inadequacies and many other reasons have prevented national cinemas from taking an important position in the international arena. Until the 1980s, enclosed local cinemas faced a great deal of competition from Hollywood companies entering the country. With these periods that can be termed as a kind of existential struggle, national cinemas have experienced great problems in terms of production and distribution, and with the years of 2000, technical conditions have changed the production and distribution conditions of the cinema and they regained their audience, even in some countries their box office passed Hollywood films. Also, the possibilities for national productions to appear in the global network have increased. Globalization, change, and progress in new communication technologies feed the concept of transnational cinema.

Lister [4] presents a concrete analysis of the relationship between new media and cinema. This analysis also exposes 
key elements that allow cinema to be discussed within the new media space. Lister, sort these key items like:

- New textual experiences: new kinds of genre and textual form, entertainment, pleasure

- $\quad$ and patterns of media consumption

- New ways of representing the world,

- New relationships between subjects (users and consumers) and media technologies,

- New conceptions of the biological body's relationship to technological media,

- The relationship of new contents of the biological body with technological tools,

- New patterns of organization and production

Lister [4] says that all of these areas include the computer-aided communication, new ways of distribution and consumption, visual reality and transformation of the entire traditional media.

Through a more focused perspective as a part of digital technologies, smartphone technologies are increasingly playing a major part in film production, distribution, and reception. The first films shot with smartphones appeared between 2005-2006. The reception of these novelties highlight the use of the new technology and its limitations becoming assets; while the newspaper The Guardian reports about the movie New Love Meetings on 14th of June 2006 indicates: "The limitations of filming with a smartphone having to film at close range, weak sound capture and the slightly shaky picture - turned out to be advantages for them, leading people to open up a little more easily." [5].

Smartphones have become an integral part of everyone, always ready and with us. That's why fiction or reality both films made with smartphones feel very close to the audience. The fact is that mobile devices offer the user the possibility of taking photos and videos everywhere and anytime. They "insert" a lens in everybody's hand: capturing reality at any moment and place of the day has never been so accessible. The possibilities this offers has not gone unnoticed, from common users to professionals. In the early examples of smartphone filmmaking, the low resolution was assessed in the context of reality effect, the quality improvement of built-in cameras and generalization of $4 \mathrm{~K}$ video brings smartphone films closer to mainstream aesthetics. The concept of aesthetics derived from this goes beyond image quality into more philosophical aspects of the smartphone use. For films made in the last years, low resolution is an option as, for instance, the mobile device iPhone $\mathrm{X}$ (and further brands and models) records in $4 \mathrm{~K}$ where there is hardly any trace of the pixel. In their short life-span, what seems to be true is that the very concept of smartphone film aesthetics is quite "mobile" itself as devices keep developing and changing very rapidly. They have mini-jack connectors; this gives the possibility of recording diegetic sound and interviewing with microphones. Further than this, the focus can be manually adjusted and filters and add-on lenses are available. The size and mobility of the device stimulate a certain use of the camera phone which translates into what might be a new shooting aesthetics. Finally, the portability factor brings the world closer to the user through the lens and the mobile screen which becomes a "window on the world" [6].

By the smartphone filmmaking on the one hand filmmakers and the audience consider how the smartphone filters the world through different types of lenses, resolutions, on the other shows the experience of environment and even further what kind of communication and information people have access to through smartphones. It is the combination of these levels and approaches that point towards a unique way of filmmaking. As an example, smartphones have impacted body language, and hence the way the body experience is incorporated into the screening and viewing process using smartphones.

It is seen in the history of cinema that technological developments have emerged as tries for new narrative forms, primarily in non-fiction films such as actuality films, news, documentary films. During the World War I and World War II, film production was intensified in the case of non-fiction genres also for the purpose of propaganda, and the development of technical equipment that could be used in actuality shootings was the basis. Non-fiction narrative forms have been influential in the development of the NeoRealism, the New Wave movements, which have an important place in the history of world cinema afterward. In this context, smartphone filmmaking will also be primarily covered within the context of widespread use and effects in actuality films, documentary films, and video activism titles. This will also give the possibility to trace the development of the fictional narratives.

\section{ACTUALITY FILMS, DOCUMENTARIES, AND VIDEO ACTIVISM THROUGH SMARTPHONE FILMMAKING}

The history of short actuality films began with the patent of Louis Lumiere's cinematograph on 13 February 1895, and then the Lumiere brothers made their first public screening on December 28, 1895, in a cafe in Paris. Along with cinematograph, Lumiere has also solved the problem of screening differently than his concurrent tries such as Bioscope in Germany, Animatograph in England, Vitascope in America. The cinematograph could easily be transported in a bag, operated with a lever without being dependent on electricity, and the same equipment could be turned into a camera with a small plug-in. Thus, the Lumiere technicians gained freedom of movement that he could send them to different parts the world, such as Egypt, Russia, Spain, Italy, Switzerland, Turkey, India, Latin America, Algeria, and Tunisia. These technicians, which Lumiere trained and sent to various countries, filmed the first actuality films and were influential for the beginning of cinema in that countries as well. They have filmed general events involving the people that also gave their audience the opportunity to see themselves and others. These films, which viewers regard as "the life itself", have laid the seeds of today's documentaries. The first actuality films taken by Lumiere can be placed at the beginning of realistic cinema [7].

Cinema has been seen as a means of mechanically reproducing reality since its early years, starting with actuality films. Whether the filmmaker is working in a nonfiction or fiction, that is, whether he is filming the real-life in-place and on-time or creating a fictional universe, he ultimately shares a message, tells a story and says something with filmic narration. Christian Metz [8] says that each film is a fiction, while Bill Nichols [9] says that 
each film is a documentary. In this context, it is possible to consider each film as an edited narration, as each shot takes time and space cutaways, it carries sound and/or images of people, their space usage, events, results that occur with the camera's presence there, in short, everything that is there. If we are to use the concept of chronotope that Mikhail Bakhtin [10] uses to put forth the time/space relationship in the novel, each narration is not only artificial, produced; the data related to the relationship between time and space at a certain time and in a certain culture are reflected in that narration as signifiers. The concept of chronotope places history and geography within the piece. The external world, that the social and historical context that the author is in, is the ground which affects it throughout. Similarly, the relationship of the reader with the time and space that he/she is in at the time of reading signifies the perception of that text by the reader.

When we look at documentary cinema in parallel with the effects of the creation of representations and the developments in digital communication technologies, with possibilities like new forms as interactive documentaries, global projects that can be easily edited with images from different sources, found footage filmmaking, large masses can reach each other without geographical position constraint, and can be the viewer, the director, and the subject of a narrative at all. Nowadays, as the boundaries between the documentarist and the audience/subject are beginning to disappear with the potential of new media and digital technology, the documentary narrative can become an effective arena of social participation as long as selfrepresentations can take place. One of the main purposes of the documentary has been put forward since its earliest examples, "to show some part of people to the rest" [11]. Since the early years of documentary cinema, documentarists have directed their cameras to different cultures. The first actuality films can be regarded as the first intercultural productions. Later on, Flaherty, Vertov, and Grierson while laying the documentary genres bases, on the one hand, gave examples of representations of cultures as well, using their films as a means of telling how they saw someone else. In traditional documentary narratives, documentaries produced 'others' representations, while 'others' could be interested in producing their own representations. Together with the developing technologies, the "other" itself can produce its own representations.

From the standpoint of independent documentarists, digital technology, smartphone filmmaking in special, gives opportunities for film production with interactive structure, online applications like Korsakow ${ }^{1}$, images open to the public, possibilities to overcome obstacles such as budget, crossing geographical boundaries, equipment requirements. In addition, a variety of materials that can be realized with much more budget and can extend the project schedule and require serious labor with traditional methods can be obtained easily from all around the world through the

${ }^{1}$ Korsakow is an open application developed by Florian Thalhofer in 2000, which can be used to create web-documentaries and other non-linear, interactive, different narrative forms. It does not require any program information and can be used on Windows and Mac. See http://korsakow.org/ participatory structure. This flow is possible through social networks such as Facebook, Twitter, MySpace, Wordpress, and YouTube and can also be effective in creating project resources through platforms such as Kickstarter, IndieGoGo. This is also important in terms of building a mass of potential audience when the project is completed [12].

As Zimmerman [13] notes, it can be said that when one can get away from the mainstream media even for one day, a very different public media practice can be seen. New media play an important role as alternative media in areas where conventional media becomes unfunctional without seeing and showing. From the perspective of video activism, this goes back the days when the television culture was dominating people's daily lives in the West and video collectives were arising after the production of Kodak's Super 8 cameras (1965) and Sony's "portapaks" (1967). Through 68 spirits, they filmed the protests of the period, social movements and built the resistance memory. Video activism emerged for social justice, in those years when civil society began to rise, as an alternative struggle against the mainstream, compromising the structure of television. This had been possible by the beginning of the '90s because video cameras have become smaller, cheaper and now even integrated into smartphones, even making it possible to use editing programs. As, in the internet environment content carries more importance than technique and the distinction between professionals and amateurs becomes dimmer due to the developments in audiovisual recording technologies and it is vital that the individuals, NGOs, different ethnic and religious groups, opposing political views, different sexual tendencies and sexual identities voice their opinions and share their untold stories in public space and find their place in the cultural arena. Thus it would be possible for them to exist with their own narratives, to reckon with the official ideology and remind the official history about their existence and to contribute to the social memory through the films they make even with their smartphones. As Schleser [14] emphasizes the role of digital moving images in the creation and promotion of new forms of agency and identity within the wider field of visual culture, the fact that anyone can participate anytime becomes essential to keep the system alive in the digital era.

\section{CHANGING ECOSYSTEM OF FICTION FILMMAKING WITH SMARTPHONES}

Digital cinematography is the process of capturing (recording) a motion picture using digital image sensors rather than through film stock. The 1990s were, in general, the transition period from analog to digital formate. Filmmakers began to benefit from this technology. In 1998, Sony produced high definition camcorders and players in professional HDCAM format. George Lucas' Star Wars: Episode I - The Phantom Menace (1999) was recorded in this format and recorded on hard drives. The director who used this camera for the first time was Pitof, the director of the French film "Vidocq" (2001) [15]. One of the most important directors used digital technology in the early periods was Mike Figgis. In the real-time movie "Timecode" (2000), he used four cameras at the same time and split the screen in four. In the same year, Michael Mann 
used digital technology and film strips together in his film "Ali". Mann used the better quality night vision of digital for his film "Collateral" (2004) [16]. Since the mid 2010s, most of the movies across the world are captured as well as distributed digitally.

The first films shot with smartphones appeared between 2005-2006. One of them is feature film SMS Sugar Man2 (2005-2006) by South African director Aryan Kaganof. This film is regarded as a revolutionary alternative way of making films with the limitations imposed by the smartphone. Another pioneering film considered amongst the first ones would be New Love Meetings (2006) by Marcello Mencarini and Barbara Seghezzi. The reception of these novelties highlights the use of the new technology and its limitations becoming assets. Even Reuters [17] referred to it as a new genre of affordable film-making, "Naked Cinema", that would put the possibilities of film creation into the hands of millions in its review for Sally Potter's Rage (2009).

There were other films that toyed with the format. With the launch of the Apple iPad in April 2010, an even greater array of opportunities launched for aspiring directors. The Silver Goat (Dir. Aaron Brookner, 2012) was the first film created for the iPad and released an app in the UK, Europe, and Latin America. When Sean Baker's breakout indie "Tangerine" arrived in 2015, its ambitious production caught a lot of attention from the film community due to the originality of its production. It was shot exclusively on a trio of iPhone 5s. The movie was not the first to use the smartphone as its primary camera, but it was the most recognized in a burgeoning field of filmmakers using phones as their primary means of production. The world's first "selfie" movie, James Carver's Starvecrow (2017), mixed smartphone, and CCTV footage to create a personal story of love and horror ${ }^{2}$.

Roger Odin [18] is one of the first ones to attempt to categorize smartphone filmmaking. Odin defines the films "made to be seen in a room by a spectator invited to adopt a specific discipline of the eye" as cinema uno and digital cinema or the films which are consumed in many different kinds of devices, as cinema due. Within cinema due the smartphone camera stands out as a different element: the camera as a prosthetic eye in the hand, as an extension of the body that makes mobile made films different, as the camera slowly integrates into the human body [18]. This reminds the Peter Crawford's definition of observational style filmmaking as the "fly on the wall" and "fly in the soup" for the participatory style filmmaking [19]. Therefore it is possible to find aesthetics that derive from the portability of the mobile device, such as the immediacy, intimacy and the every day which a smartphone camera can deliver and which become a unique aspect of mobile filmmaking, same as Soderberg describing his aim to use smartphones for his latest film Unsane(2018) [20]. This aesthetic emphasizes the importance of location, space and also nonspace - being here, being anywhere, but here is

2 For the list of films shot with smartphones https://filmschoolrejects.com/movies-shot-with-phones/ http://www.indiewire.com/2018/03/movies-shot-on-iphones-unsanetangerine-shorts-1201941565 where the smartphone is and not any fixed place, via immersion.

When the smartphone made films aimed for phone viewing, small screen, the framing design will affect many aspects to be considered, from the size of the screen to the screen light becoming a vital component of the represented image as the phone is activated. But today, films made with smartphones are also aiming at the big screen. And now smartphones are used for films made to be screened in movie theaters as well. Unsane, (Dir. Steven Soderberg, 2018) premiered and was in competition at the one the world's most prestigious film festival, Berlin International Film Festival. In the film, Claire Foy is staring as a young woman who is institutionalized against her will. She believes she is being followed by a stalker, but the surrounding professionals insist she is psychotic. Using the iPhone, Soderbergh got shots that would make audiences feel uncomfortable, in the same fashion that Foy was experiencing this nightmare.

\section{CONCLUSION}

It is obviously important that the non-governmental organizations, different ethnical and religious groups, dissident political opinions, different sexual orientations and sexual identities, carry the non-seen images, unheard voices, unknown stories to the public sphere, apart from mainstream cinema. It is only possible that they square up with the official ideology, reminds the other history than the official history and contributes to the social memory with their own narratives. At this point, as not being commercial movies, independent productions differentiate from other cinematic productions and act as an efficient narration to raise public awareness, to increase freedom of expression, to try different art forms etc. With digital technologies and now with smartphone filmmaking, cinema had become a more attainable mean of expression. The film takes a much faster and less costly way to go to the movie theaters after shooting with digital cameras and editing digitally. This also affected fiction films with a change in their narrative structures and discourses, besides a big rise in production numbers.

We may easily say that examples of smartphone filmmaking open ways for the latter with their structures and discourses. These movies have narratives that deviate from mainstream and dominant ideology; they are critical towards power; they present unusual variety in subject matters; they particularly prefer different genres like documentaries, docudramas as a means of expression; they are self-funded; their screenings can organized out of mainstream distribution channels; they are produced with a fresh new language, new representations, and selfrepresentation; they exploit technological opportunities of the digital age. They strongly lean on a generation's behavior being recorded and made publicly available on social media for future audiences. Every attempt to explain the style and aesthetics of smartphone made films and better understand their potential might define the characteristics of a possible new language. As with all emergent media forms, the content and themes reflect and exemplify the tools of their making - ultimately creating new ways of storytelling, 
new modes of production and new types of audience engagement. As such, these pioneering and visionary examples of smartphone films will undoubtedly take their place as significant innovations in the history of cinema. As every other day, new equipment is released for shooting with smartphones, it is obvious that as more directors adopt the format into feature films, more attention and accessories will be made to further the abilities of smartphone. Just to increase cinema literacy new publications will emerge, like Montgomery's Smartphone Video Storytelling [21], more and more every day, guiding new cinematographers about the huge potential.

Beyond the original intention of making and screening any film, the social and cultural implications that it carries lead to such a global network that the narration becomes an important means of intercultural interaction. As Bloom noted [22], one of the basic principles of cinema literacy is to be open to different perspectives, and Smartphone filmmaking movies provide an important practice area for this principle to work. It is, therefore, worthwhile to read Smartphone filmmaking movies as a complex system of new goals, new publications, and new information. Also, Soderberg defines his experience in Unsane as potentially one of the most liberating experiences that he has ever had as a filmmaker [23].

\section{REFERENCES}

[1] Claire Foy and Matt Damon - in a film shot on a smartphone [Online]. Available: http://www.bbc.com/culture/story/20180223claire-foy-and-matt-damon-in-a-film-shot-on-a-smartphone

[2] C. Baker, M. Schleser, and K. Molga, "Aesthetics of mobile media art," Journal of Media Practice, vol. 10, no. 2-3, 101-122, 2009.

[3] A. Lopez, "Facing up to Hollywood," in Reinventing Film Studies, C. Gledhill and L. Williams ed. London: Arnold Publishers, 2000, pp. 419-437.

[4] M. Lister, New Media: A Critical Introduction, London: Routledge, 2003.

[5] Full-length film shot on phone. (2006). The Guardian. [Online] Available: http://www.guardian.co.uk/film/2006/jun/14/news2

[6] C. Barker, Global Television: An Introduction, Oxford: Blackwell Publishers, 1997.

[7] E. Barnouw, Documentary: A History of the Non-Fiction Film, New York: Oxford University Press, 1993.
[8] C. Metz, Psychoanalysis and Cinema, London: The Mc Millan Press, 1982.

[9] B. Nichols, Introduction to Documentary, Bloomington: Indiana University Press, 2001.

[10] M. Bakhtin, Karnavaldan Romana, İstanbul: Ayrıntı Yayınları, 2001, pp. 295-312.

[11] P. Rotha, Belgesel Sinema, Istanbul: Izdüşüm Yay, 2000.

[12] J. Nelson, "Social media as a filmmaking narrative tool," Image \& Text: A Journal for Design, vol. 20, pp. 146-161, 2012.

[13] P. Zimmermann, "Public domains: Engaging Iraq through experimental digitalities," in Rethinking Documentary: New Perspectives, New Practices, Maidenhead /New York: McGraw Hill, 2008, pp. 284-98.

[14] M. R. Schleser, "Smart [Phone] Filmmakers >> Smart [Political] Actions," in The Evolution of the Image, Routledge, 2018, pp. 113123.

[15] İ. Canikligil, Dijital Video ile Sinema, İstanbul: Pusula, 2007.

[16] R. Bergan, Film, İstanbul: İnkilap, 2008.

[17] "Rage" strips down at Berlin. (2009). [Online]. Available: https://www.reuters.com/video/2009/02/10/rage-strips-down-atberlin?newsChannel=entertainmentNews \& videoId $=98469$

[18] R. Odin, "Question poseéa la thórie du cinema par les films tournés sur telephone portable," in The Very Beginning and The Very End. Film Theory in Perspective, 2009, pp. 363-373.

[19] P. Crawford, "Film as discourse: The invention of anthropological realities," in Film as Ethnography, Manchester: Manchester University Press, 1992.

[20] Steven Soderbergh - Unsane exclusive interview. [Online]. Available: https://www.youtube.com/watch?v=n7zC9gfi60E

[21] R. Montgomery, Smartphone Video Storytelling, New York: Routledge, 2018.

[22] K. Bloom and K. M. Johnston, "Digging into YouTube videos: Using media literacy and participatory culture to promote cross-cultural understanding," Journal of Media Literacy Education, vol. 2, no. 2, p. 3, 2013.

[23] Steven Soderbergh says he's done directing Studio movies and wants to only shoot on iPhones - Sundance 2018. [Online]. Available: http://www.indiewire.com/2018/01/steven-soderbergh-interviewsundance-iphone-unsane-1201921769/

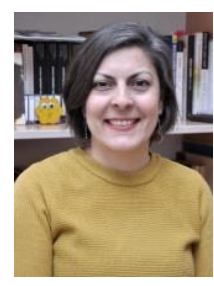

Nihan G. Işıkman is currently a lecturer at Baskent University, Faculty of Communication, Department of Radio Tv Cinema, giving the lessons such as documentary cinema, documentary film making, directing in cinema, production in cinema. Her work focuses on different forms of narrative in documentary cinema, cinema, re-presentation of reality. She has won awards for documentary films she has produced and directed and has participated in international festival programs. Since 2014 she has been the documentary program coordinator at the AIFF and a member of the executive board of World Mass Media Research Foundation. 